\title{
Aportaciones a la Historia de la Documentación: evolución y contexto historiográfico
}

\author{
José LÓPEZ YEPES \\ Universidad Complutense de Madrid \\ yepes@ccinf.ucm.es \\ Federico HERNÁNDEZ PACHECO \\ Universidad Nacional Autónoma de México \\ profhern@yahoo.com
}

Recibido: 01/02/2011

Aceptado: 18/02/2011

\section{RESUMEN:}

Repaso a la historia de la Documentación a través de las grandes civilizaciones y las distintas etapas que han conformado lo que hoy es la cultura occidental: desde el imperio asirio hasta el siglo XVIII o "Siglo de las luces". A través de este estudio podemos comprender cuál ha sido la evolución y los inicios que han conformado lo que hoy entendemos por Documentación.

Palabras clave: Documentación, Historia de la documentación, Evolución, Contexto historiográfico.

Contributions to the History of Documentation: Evolution and historiographical context

\begin{abstract}
:
Revisiting the history of documentation through the great civilizations and the various stages that have shaped what is now Western culture: from the Assyrian empire in the seventeenth century. Through this study we can understand what has been the evolution and the beginnings that have shaped what we now mean by documentation.
\end{abstract}

Key words: Documentation, History of documentation, Evolution, Historiographic Context.

\section{LA PROTOHISTORIA DOCUMENTAL}

Los primeros indicios de trabajo documental propiamente dicho se remontan a los tiempos del imperio asirio (más de 30 siglos a. C.) según han revelado las exploraciones arqueológicas de Mesopotamia, principalmente en Larsa, Uruk, Ur, Sippara, Cala y Nínive, de cuyas ruinas se han extraído, por millares, los famosas tabletas cubiertas de inscripciones que actualmente atesora en su gran mayoría el Museo Británico. Así, la 
más célebre biblioteca fue la descubierta en Koyundjik, entre las ruinas del palacio de Senaquerib, fundada y engrandecida por Asurbanipal.

De Uruk, ciudad sumeria situada al SE de Irak, se guardan cientos de tabletas de arcilla que datan de 2000 años antes de cristo y que muestran la organización de dicha ciudad con listas de nombres, de personas y bienes. Estas listas en la mayoría de los casos resulta el precedente de la actual bibliografía, pues han sido enumeraciones y catálogos con distintas motivaciones, que entre otras cosas, ayudaron a componer la cronología y las grandes conmemoraciones dinásticas. ${ }^{2}$

No obstante, aún cuando no se sabe con exactitud cuáles eran los principios de clasificación de las tabletas, ha de suponerse que existían catálogos, pues en los escritos cuneiformes se registraba el título y el autor, que pudieron utilizarse para facilitar la localización de los materiales. Y en efecto, de la época de Asurbanipal se encontraron tabletas de arcilla similares a una guía impresa o a una lista rudimentaria de un archivo, algunas de éstas registraban un primitivo sistema de localización mediante la grabación del título o las palabras del comienzo de la obra. Igualmente, cabe destacar el descubrimiento de las listas del archivo de Ebla, en Siria, compuesto por miles de tabletas de arcilla de distintos tamaños y formas irregulares que registraban nombres de dioses, profesiones, objetos, dibujos y templos, plantas minerales y narraciones. Las excavaciones de Ebla nos han hecho ver que las funciones documentales estaban definidas en sus líneas esenciales hace 4,500 años, pues ha podido deducirse que las tabletas se colocaban en estanterías atendiendo su contenido mediante signaturas en los lomos.

\section{GRECIA}

No puede hablarse de la historia de la documentación sin hacer un profundo análisis de su presencia en la civilización griega, ya que fue la primera que llevó a efecto una producción literaria organizada de excelente calidad para el resto de las culturas; así como una importante producción de carácter científico, religioso y jurídico en respuesta a la constante búsqueda de un orden permanente en su civilización.

Será en el periodo comprendido entre Heródoto (484/425 s.V) y Tucídides (460-396 s. V/IV), cuando se produce la evolución de la oralidad a la cultura del libro. Este hecho

\footnotetext{
${ }^{1}$ Fue la última biblioteca fundada por los asirios, a cargo del rey Asurbanipal, famoso por hacer frente durante su reinado a una fuerte rebelión encabezada por su propio hermano. Esta biblioteca fue descubierta a mediados del siglo pasado por dos ingleses cuando empezaron a excavar en Nínive -ciudad más destacada del Imperio Asirio dedicada a la agricultura y situada en el curso alto del río Tigris- y aparecieron unos 30,000 fragmentos de tabletas de arcilla enterradas en las ruinas del palacio real y la ciudad. Dicho descubrimiento hizo que avanzara el desciframiento de la escritura cuneiforme y sorprendió a los estudiosos cuando se supo que entre las tabletas había unas que contenían el Poema de Gilgamesh, el poema conservado más antiguo de la humanidad. En. Escolar Sobrino, Hipólito. Historia de las bibliotecas. 3ª . Ed. Salamanca. Madrid: Fundación Germán Sánchez Ruipérez: Pirámide, 1990. Pág. 16.

${ }^{2}$ Arnau Rived, Pilar. "Documentación. Hitos históricos”. Madrid, Mundarnau, 1999. p. 23
} 
no significa que anteriormente no hubiese testimonios escritos, pero éstos se elaboraban para ser conservados en templos o archivos del estado y su autoría se hallaba en las clases sacerdotales y entre las dirigentes. Testimonios nos informan que Psístrato (607527 , s. VII/VI) y Polícrates (?- 522, s. VI) recopilaban libros y fundaban bibliotecas, sin olvidar las leyes escritas y presentadas por Dracón (?-650, s. VII) y Solón (638-558, s. VII/VI), quienes además escribieron y publicaron poemas propios ${ }^{3}$. Lo cierto es que estos libros no estaban destinados a circular de una forma activa entre la población. Es decir, durante la etapa arcaica griega la forma de "lectura" fue la oralidad; su publicación responde a una representación oral en y para determinados acontecimientos sociales. ${ }^{4}$

Será por tanto entre el siglo V y el IV a. C. (etapa clásica griega) cuando se produce la mayor eclosión de la palabra escrita en la revolución de las técnicas del pensamiento que caracteriza el citado siglo V. Los libros empiezan a publicarse y a circular con fluidez entre el pueblo; y no sólo encontramos textos de los trágicos como Eurípides, Sófocles o Esquilo, si no manuales técnicos como los de Hipodamo (sobre el urbanismo), Policleto (sobre la simetría del cuerpo humano) o Ictino (sobre el Partenón). Durante este siglo en Atenas, centro cultural, ya había muchas personas dispuestas a producir copias de libros ante la demanda del pueblo, y es en una obra de Aristómenes, Los embaucadores, cuando aparece por primera vez el vocablo griego bibliopóles para referirse al termino <librero>. Así, en la comedia de Aristófanes, Las aves, se describe a los ciudadanos acudiendo precipitadamente a las librerías, que en este siglo ya se habían convertido en un lugar social y de conversación para el público con intereses literarios.

Fue el comercio el que dio lugar al establecimiento de las colecciones privadas de libros durante el siglo V a. C. y con mayor frecuencia durante el siglo IV a.C. Así por ejemplo, es interesante resaltar la biblioteca privada de Platón, muy abundante, que incrementó al adquirir la del filósofo pitagórico Filolao. De igual modo, encontramos la de Aristóteles, muy numerosa y ordenada científicamente en el Liceo, gimnasio al este de Atenas. Según nos indica Estrabón (s.I a.C) Aristóteles enseñó al emperador de Egipto el método para organizar una biblioteca. Tal era la grandeza de ésta, que después de pasar por varios dueños acabó en manos de Sila en el 86 a.C., trasladándola a Roma. ${ }^{5}$

Por tanto, en el primer tercio del siglo IV a.C. los libros se establecieron de una manera firme. Este hecho se vio plasmado con la transformación que Alejandro Magno realizó en el mundo griego: Atenas perdería su supremacía literaria y política y los nuevos reinos creados por Alejandro se convertirían en esenciales pilares políticos,

3 SVEnBRO, J. (1988): Phrasikelia. Anthopologie de la lecture en Grèce ancienne. París; NIEDDU, G.F. (1984): Testo, scrittura, libro nella Grecia arcaica e classica : note e osservazioni sulla prosa scientifico-filosofica, en Scrittura e Civilità, VIII. pp. 213-61.POSNER, E. (1972) Archives in the Ancient World, Cambridge. pp. 91-110.

${ }^{4}$ Para una mayor información sobre este periodo veáse ONG, W.J. (1982): Orality and Literacy. The technologizing of the world. Londres-Nueva York.

${ }^{5}$ Sobre el comercio de libros y las bibliotecas de Platón y Aristóteles véase, MILLARES, A. (1993): Introducción a la historia del Libro y a las Bibliotecas. Madrid. 5 ed. pp. 227-228; ESTRABÓN, Geografia, XIII, 1, 54. PLUTARCO, Sila, cap. 26. 
sobre todo el Imperio Persa. Desde Macedonia hacia el Este, empujaban las tropas de aquél logrando derrotar al emperador persa Darío III en la batalla de Iso, la cual fue clave para tomar la franja costera fenicia y por extensión al país egipcio. Una vez en éste, se granjeó la confianza del clero, reconstruyó y restauró templos y dividió el país en tres zonas administrativas, dejando al frente de dichas zonas a un egipcio; eso sí, junto a éstas siempre habría un militar macedónico. De igual forma trasladó la capital de Menfis -antiguo centro de poder faraónico-, hacia Alejandría - de nueva fundación-.

Años después, con la muerte de Alejandro Magno, el Imperio que se logró conformar se desintegraba bajo sus herederos. Así, tiempo más tarde en Egipto, que estaba en manos de los Lágidas, Ptolomeo I Sotor llama a Demetrio de Felero, discípulo de Aristóteles ${ }^{6}$, el cual organizó el Museo de Alejandría, donde se conformó el Museo y la mítica Biblioteca, cuya época de gran esplendor llegó con Ptolomeo II. Estamos pues, ante una verdadera excepción de la Edad Antigua, a la vez que ante el primer atisbo de luz en la humanidad sobre organización seria y sistemática del conocimiento. En dicha institución se llegaron a congregar casi medio centenar de sabios y estudiosos provenientes de todo el mundo griego que se dedicaron a crear, recopilar y catalogar las obras existentes, así como las distintas formas del saber vigentes hasta ese momento. A su vez se convirtió en uno de los instrumentos más poderosos para la helenización de la zona del Nilo. ${ }^{7}$

En aquella biblioteca había diez grandes laboratorios de investigación, ya que la labor de ésta no sólo consistía en recopilar y catalogar literatura griega, sino también en comentar las obras científicas y elaborar ediciones muy rigurosas de alta calidad. Además había fuentes, columnas, jardines botánicos e incluso un zoológico con animales de la india y del Sahara, había un laboratorio de anatomía y un observatorio astronómico. Sin embargo, el gran tesoro de aquella biblioteca, consagrada al Dios Serapis, era su colección de libros, la cual se calcula llegaba a un millón ejemplares. ${ }^{8}$

En esa época se contrataba filólogos para que viajaran por el mediterráneo y adquirieran todas aquellas obras literarias de gran importancia. En ocasiones, los ejemplares prestados por otras ciudades para su copia nunca llegaron a devolverse, muy a pesar de las elevadas fianzas pagadas de antemano. Así, el gobierno egipcio llegó a

\footnotetext{
${ }^{6}$ No es de extrañar que García Morales cite como base para los sistemas protohistóricos de la catalogación las ideas aristotélicas. En Moreiro González, José Antonio. "Introducción bibliográfica y conceptual al estudio evolutivo de la documentación". PPU, Barcelona, 1990. Pág. 42.

${ }^{7}$ Alejandría fue la ciudad más grande de aquellos tiempos, en donde había una inmensa biblioteca y un instituto de investigación en los que trabajaron las mentes más privilegiadas del mundo antiguo, fue el cerebro y la gloria de una de las civilizaciones más importantes del planeta. Dicha biblioteca fue el primer instituto de investigación del mundo en donde se estudiaba todo el cosmos entero. Es ahí donde trabajaba Eratóstenes, quien había calculado con exactitud la curvatura de la tierra con una gran precisión; Hiparco, quien hizo un mapa de las constelaciones y midió el brillo de las estrellas; Euclides, quien brillantemente sistematizó la geometría; Dionisio, quien definió las partes del lenguaje; Erofilo, un físiólogo que identificó el cerebro en lugar del corazón como la sede de la inteligencia; Arquímedes, el gran genio de la mecánica hasta los tiempos de Leonardo Da Vinci; y el astrónomo Ptolomeo, quien recopiló mucho de lo que ahora es la falsa ciencia de la astrología. En: Sagan, Carl. "En la orilla del océano cósmico" [Vídeo]. Barcelona: Midas Home Vídeo, 1990. Serie Cosmos.

${ }^{8}$ Sagan, Carl. Op. cit.
} 
confiscar la documentación que portaban los barcos que atracaban en el puerto de Alejandría.

La importancia del trabajo documental de esta biblioteca fue porque en ella se da el antecedente más remoto de la bibliografia: los Pinakes, que eran repositorios para clasificar los rollos de acuerdo con sus contenidos y relacionarlos con sus géneros científicos. Calímaco, bibliotecario de aquella institución, clasificó a todos los autores griegos en categorías y utilizó su propia terminología en unas "Tablas". Éstas serían idénticas a las categorías que había utilizado para clasificar y archivar los fondos de la biblioteca, por lo tanto, había creado una herramienta de vital importancia para determinar la existencia de las obras. Se sabe además que la caña de papiro que crece en Egipto se utilizó para cada uno de estos millones de volúmenes de rollos escritos a mano. En esta biblioteca nació la erudición y se elaboró lo que se conoce como el "canon", que serviría de modelo para las épocas posteriores. Este canon no era una clasificación bibliográfica, si no una lista de los escritores que eran considerados como modelos en su género literario. En tiempos de Ptolomeo II (285-247), se organizó una segunda biblioteca, el Serapeum, con 48.000 volúmenes, que se vio incrementada por el aporte de obras que realizó Ptolomeo Evergetes (246-221). ${ }^{9}$ Desafortunadamente la biblioteca fue destruida por un incendio en el 48 a.C., siendo una catástrofe para la cultura de la humanidad. Una gran parte de la literatura griega se perdió para siempre, salvándose sólo una pequeña parte, y del resto, únicamente quedan unos cuantos fragmentos que sólo nos sirven de vestigio. ${ }^{10}$

Ninguna otra biblioteca griega pudo compararse con la de Alejandría. Los reyes de Egipto que sucedieron a Alejandro, consideraban los avances de la ciencia, la literatura y la medicina como los tesoros del imperio. Durante siglos apoyaron generosamente la investigación y la erudición, una actitud civilizada compartida por algunos jefes de Estado, tanto de entonces como de ahora.

Otra de las grandes bibliotecas fue Pérgamo, en donde el rey Atalo I, a mediados del siglo III, fundó una biblioteca que quería rivalizar con la de Alejandría. Bajo su sucesor, Eumenes II (197-158), fue aumentada, organizada y sistematizada, alcanzando grandes dimensiones y una elevada importancia en el desarrollo de la literatura científica en las bibliotecas. ${ }^{11}$ En esta biblioteca además de rollos de papiro se utilizaban pieles de animales como materiales de escritura, a los cuales se les dio el nombre de "pergamené". Al parecer los rollos se catalogaban por temas, lo cual permitía saber de inmediato si la colección incluía la obra que se quería consultar. ${ }^{12}$ Los griegos,

${ }^{9}$ DAIN, A. (1949): Les manuscrits. París. p. 99. Sobre el aporte de libros de este monarca a la biblioteca, AULO GELIO, Noches Áticas, VI, 17.

${ }^{10}$ Por ejemplo, se sabe que en aquellos tiempos existió un libro escrito por Aristarco de Samos, en el cual defendía la teoría de que la tierra era un planeta más que giraba alrededor del sol y que las estrellas estaban enormemente lejos. Su teoría era correcta, pero tuvo que esperar dos mil años para su redescubrimiento. Si se multiplica la pérdida de este tipo de obras se podría apreciar la grandeza del logro de la civilización clásica y la tragedia de su destrucción.

${ }_{11}$ Sobre la biblioteca véase MILLARES, A. (1993): Introducción a la .. op. cit. 5.p. 230; CALLMER, C. (1944): Die antiken bibliotheken, luna-Leizpig. pp. 148 ss.

${ }^{12}$ Escolar Sobrino, Hipólito., Op. cit. 
habitantes de estas civilizaciones, asimilaron lo más provechoso de todas las culturas, siendo capaces de originar un pensamiento sobre el que se fundamenta la civilización occidental.

\section{EL IMPERIO ROMANO}

Acertadamente como indica Kleberg, "Roma conquistó por la fuerza de sus armas el área de la cultura griega, pero Grecia conquistó con su cultura al joven pueblo victorioso ${ }^{\prime \prime}$. Es innegable la influencia griega ejercida en la cultura latina y que por ende también se vería reflejada en las colecciones y el comercio de libros, así como en la idea de las bibliotecas en Roma. Ahora bien, estos conceptos fueron desarrollándose paulatinamente a lo largo de la historia de Roma hasta su total formación y consolidación. Durante los primeros tiempos romanos, la cultura escrita estaba en manos de la casta sacerdotal y de la clase gentilicia y dentro de éstos era la clase dirigente su autor. Así, encontramos los commentari augurum, los libris Sybillini o los commentarii a las magistraturas y las laudationes colocados todos ellos en lugares secretos; es decir los libros no estaban al alcance del pueblo, sino en aquellos grupos en los que recaían los conocimientos fundamentales de la $u r b s$, el religioso y el jurídico. ${ }^{14}$ A lo largo de los siglos III, II y I a.C., dentro de la etapa republicana, entran en Roma bibliotecas completas griegas obtenidas de los botines de guerra. Así el cónsul Lucio Emilio Paulo tras la batalla de Pidna en el 168 a.C., llevó a Roma la biblioteca del reino macedonio en el 86 a.C. Sila se hizo con la biblioteca de Aristóteles y en el 70 a.C. Lucio Licino Luculo la del Ponto Euxino, de enormes dimensiones. Estas bibliotecas se convirtieron en bibliotecas privadas junto con las ya existentes de personajes tan ilustres como Cicerón, Tito Pomponio Ático, Marco Terencio Varrón ${ }^{15}$. Las obras estaban escritas en forma de rollo, tan característico en el mundo griego y de clara influencia egipcia $^{16}$. Es todavía la época de los volumina de papiro hasta que años más tarde la literatura latina pasara al codex, difundiéndose de una manera más rigurosa en la edad media $^{17}$. Así, los libros griegos serían modelos en los que se inspirarán los nuevos libros que nacerán en Roma, tales como la Odisea de Livio Andrónico y el Bellum Punicum de Nevia, que serán escritos en volumina. Las bibliotecas privadas se hallaban situadas

${ }^{13}$ KLEBERG, T. (1995): Libros, editores y público en el mundo antiguo. Madrid. p. 65.

${ }^{14}$ CAVALLO, G. y CHARTIER, R. (2001): Historia de la lectura en el mundo occidental. Introducción. Madrid. p. 31.

${ }^{15}$ Sobre las bibliotecas de conquista, véase BLANCK, H. (1992): Das Buch der Antike. Munich. pp. 152-160; CASSON, L.(2001): Libraries in the Ancient World. New Haven y Londres. p. 61 y ss. El propio Varrón escribió la obra Sobre las Bibliotecas, en tres volúmenes, de la que se servirían otros autores, entre otros Suetonio, como fuente. Esta obra no ha llegado hasta nuestros días.

${ }^{16}$ La forma de libro era el rollo de papiro, que se componía de un número variable de folios con columnas de escritura y se distinguía según su altura y grosor, KLEBERG, T. (1995): Libros, editores y...op cit. 13. p. 76 .

${ }^{17}$ Sobre la difusión del codex en Roma véase HAESLST, J. V. (1989): Les origines du codex, en Blanchard (ed.), Les débuts du codex, Brepols-Turhout. pp. 13-35. Así mismo, SKEAT, T.C. (1983): The birth of the codex. Oxford. 
en las villas de sus propietarios inmersas dentro del ambiente del otium entre amigos y libros. Se ubicaban junto a pórticos, salas de recreo, pinacotecas y jardines donde se facilitaba las relaciones sociales entre las clases cultas, evocando las instituciones helenísticas- alejandrinas de la academia, gymnasium, lyceum, o palestra ${ }^{18}$. Es importante destacar que ya en época de Cicerón y su hermano Quinto existía un bilingüismo cultural (griego y latín) en las bibliotecas, como se atestiguan en las suyas. ${ }^{19}$

Un ejemplo destacable de este tipo de bibliotecas privadas lo encontramos en la Villa de los Papiros en la ciudad de Herculano. Parece ser que pertenecía al suegro de César, Lucio Calpurnio Pisón Cesonio, cónsul y censor (58-50 a.C.), quien tomó a su cargo al epicúreo Filodemo de Gadara, evidenciándose así su afinidad con el helenismo. En su biblioteca se encontraron no solo numerosos volúmenes de este filósofo si no de importantes autores griegos y romanos, como evidencian los restos de papiros carbonizados que se encontraron. La entrada de la villa en torno a un peristilo se organizaba según el modelo del gymmasium griego, donde se situaban las obras literarias. ${ }^{20}$ El número de las bibliotecas privadas se fue incrementando a los largo de los siglos I a.C. y I d.C., convirtiéndose en un signo distintivo de toda aquella persona adinerada, incluso a pesar de no poseer una amplia cultura o un cierto interés en la lectura. El libro se convertía pues, en un signo de rango distintivo en la sociedad. Es interesante resaltar que durante el periodo republicano, sobre todo a partir del siglo II a.C, (el siglo de los Escipiones) aumenta el número de librerías y el propio comercio librero. Las librerías se convirtieron en centros de reunión social donde acudían individuos con intereses literarios o científicos en busca de publicaciones antiguas o recientes (ya vimos casos similares en Grecia). Allí los libros estaban colocados en armaria o sobre estanterías denominadas nidi, así como expuestos sobre las mesas, mensa. $^{21}$

Cicerón nos ilustra sobre la condición social de las personas que acudían a las librerías y que se interesaban por la historia; eran de modesta condición como los artesanos y ancianos. Pero según el autor lo hacían por la voluptas, es decir por el placer de la lectura, no por la utilitas que pudieran tener las obras literarias o científicas, siendo éste el fin del lector intelectual. ${ }^{22}$ No podemos obviar el hecho de que el comercio literario fue el que propició la aparición de las bibliotecas públicas en Roma. Así, en el año 39 a.C., gracias a Cayo Asinio Polión se abrió la primera biblioteca

${ }^{18}$ ZANKER, P. (1992): Augusto y el poder de las imágenes. Madrid. p. 46.

${ }^{19}$ CICERÓN, Cartas a Atico, I, 20, 7; II, 1, 12; 20, 6.

${ }^{20}$ Sobre esta biblioteca véase ALONSO, V. (2003): Las primeras bibliotecas en Roma (romoteca), en Revista General de Información y Documentación, 13, $\mathrm{n}^{\mathrm{o}} 1$. p. 41 y nota 12; así mismo y con un amplio desarrollo sobre la biblioteca, MILLARES, A. (1993): Introducción a la historia...op. cit. 5. p. 231-232 y nota 16 .

${ }^{21}$ SIDONIO APOLINAR, Epigramas, II, 9, 4; MARCIAL, Epigramas, I, 117, 15; PSEUDO ACRÓN, Ad. Hor. Ep.I, 20, 2.

${ }^{22}$ CAVALLO, G. (1998): Entre el volumen y el codex. La lectura en el mundo romano, en Cavallo, G. y Chartier, R. (dir), Historia de la lectura en el mundo occidental. Madrid. p. 116; CICERÓN, Quaestiones Tusculanae, I, 6. 
pública con el botín de su campaña en Dalmacia ${ }^{23}$. Es notorio indicar que César fue quién ideó el proyecto de la apertura de esta biblioteca encargando a Varrón dirigir ese cometido, pero dado que fue asesinado, su proyecto no pudo llevarse a efecto. ${ }^{24}$

De esta forma Asinio Polión construyó la biblioteca en el denominado Atrium Libertatis, cerca de la Curia. La biblioteca estaba dividida en dos secciones, respondiendo al bilingüismo dialéctico del momento ${ }^{25}$. Además la adornó con imágenes de escritores que aparecían expuestas en el atrio.

Es en época ya del Imperio (aunque ya se inició a finales de la República) cuando se aprecia un giro en las prácticas de lectura, sobre todo porque se asiste a un mayor índice cultural entre la población, a una mayor difusión de la alfabetización. La capacidad de leer y de cultura literaria se incrementa ya entre los diversos estratos sociales romanos. Entre el público lector se encontraban los círculos aristocráticos, así mismo los gramáticos y retóricos, e incluso esclavos y libertos; y sobre todo un nuevo grupo cultural que se situaba entre las clases media y bajas. ${ }^{26}$

Por lo tanto las bibliotecas públicas que se abren durante el Imperio pueden describirse como "eruditas", donde se acudía para consultar obras antiguas, cotejar textos o leer fragmentos. Son bibliotecas abiertas a cualquier tipo de lector, aunque solían ser frecuentadas con más asiduidad por doctos y literatos de profesión, un público de nivel medio alto ${ }^{27}$. Las obras literarias escritas en los rollos se conservaban o bien en cajas de madera con rótulos de pergamino o en estanterías con etiquetas (el index o titulus) de manera que el libro pudiera ser fácilmente identificable. ${ }^{28}$

La época Augusta es el periodo más rico de florecimiento literario romano. Es la época de Ovidio, Virgilio, Tito Livio...autores que escriben con un gran sentimiento nacional "ordenado" desde los círculos de poder para el control de la sociedad por parte de la clase imperial. De ahí que el florecimiento de bibliotecas públicas en este periodo se debiera, entre otros factores, a convertirse en monumentos destinados a conservar la memoria histórica; sin obviar que también se presentan como lugares de esparcimiento de culto de la vida urbana. ${ }^{29}$

Así de esta manera, Augusto estableció en Roma dos bibliotecas bilingües de libre acceso: una en el Pórtico de Octavia, que se destruyó en tiempos del Emperador Tito (40-81) y otra en el Palatino, que duró hasta la época de Constantino (306-337). Se edificaron con una novedad referente a las griegas y es que los depósitos de volúmenes y la sala de lectura se ubicaban en una misma área y no en espacios separados. Había

\footnotetext{
${ }^{23}$ PLINIO, Historia Natural, VII, 30; 35; 2.

${ }^{24}$ Es Suetonio quien nos indica este hecho: "abrir al público el mayor número posible de bibliotecas griegas y latinas, para lo cual encomendó a Marco Varrón que cuidara de la compra y clasificación de los libros". SUETONIO, Cesar, XLIV, 2.

${ }^{25}$ Así lo recoge San Isidoro: "Primus romae bibliotecas publicavit Pollio, graecas latinasque”. SAN ISIDORO, Etymologiae, VI, 5.

${ }^{26}$ CAVALLO, G. (1998): Entre el volumen y el ...op.cit.22. p. 119.

${ }^{27}$ Sobre las bibliotecas públicas en Romas véase, BLANCK, V. (1992): Das buch in ...op. cit. 15. pp. 160-178.

${ }^{28}$ MANGUEL, A. (2002): Una historia de la lectura. Madrid. pp. 187-188.

${ }^{29}$ CAVALLO, G. (1998): Entre el volumen y el ...op. cit. 22. pp. 33; 120.
} 
dos salas de lectura, absidiales y contiguas y se abrían a un pórtico exterior, donde se paseaba y se leían las obras; en su interior en nichos de pared se ubicaban los armarios para guardar los libros, entre estatuas de ilustres personajes. Incluso conocemos los nombres de los jefes bibliotecarios de ambas bibliotecas, el gramático Pompeyo Macron y Cayo Julio Higinio. ${ }^{30}$

Desde época de Augusto y con las siguientes dinastías se abren numerosas bibliotecas en todo el territorio del Imperio. Las más destacadas fueron las de Vespasiano (69-79 d.C.) y la de Trajano (98-117). La primera denominada Bibliotheca Pacis, se fundó en el 75 d.C., dentro de un amplio recinto que se desarrollaba en torno a un patio porticado con un templo (Templum Pacis) en su cabecera; contenía dos estancias donde se almacenaban las obras griegas y latinas, especializándose en escritos raros de gramáticos y anticuarios latinos. La segunda, la famosa biblioteca Ulpia, erigida en el 100 d.C., en el foro del mismo emperador y trasladada posteriormente a las termas de Diocleciano. ${ }^{31}$

Sobre este último dato resulta interesante resaltar que en ocasiones algunas de estas bibliotecas públicas imperiales se construían al lado de las termas más importantes de las ciudades. Sus fondos bibliográficos eran de diferente naturaleza al de las anteriores, ya que en ellas se encontraban literatura de entretenimiento, que el público leía mientras paseaba por las diferentes áreas termales. ${ }^{32}$

A mediados del siglo IV, la urbs de Roma contaba con veintiocho bibliotecas públicas. En la Galia y en Africa se abrieron otras tantas gracias a donativos de particulares $^{33}$. Es notable destacar que ya en la Antigüedad existía la censura con la que se rechazaban obras no sólo por razones literarias o filológicas sino respondiendo a razones de índice moral o político. ${ }^{34}$

Durante el Imperio también las bibliotecas privadas tienen su continuidad. De hecho en esta época se generaliza la costumbre de dotar a las propias casas de bibliotecas, en un intento quizás de hacer ostentación de poder económico y de "cierta cultura". En estos momentos libros y lecturas eran una muestra de bienestar y vida adinerada. Entre las clases altas romanas se desarrolló una verdadera "bibliomanía"; las nuevas clases pudientes llenaban sus casas de innumerables libros. Los escritores relatan en sus obras ejemplos de esta situación; así Séneca escribe "que los que compran libros por millares, son culturalmente hablando inferiores a sus propios sirvientes; ni siquiera han llegado a leer los titulos de todos sus libros. Los tienen por meros adornos, y para ellos la biblioteca viene a ser un complemento de la casa como una buena sala de baño". Luciano sostiene que "las bibliotecas son lugares de esparcimiento para los

\footnotetext{
${ }^{30}$ Sobre las bibliotecas véase SUETONIO, De gramm., 21, 3; Augusto, 29, 3; Ovidio, Tristias, 1, 7172. DION CASIO, Historia Romana, LIII, 1, 3; LXVI, 24, 2; ALONSO, V. (2003): Las primeras bibliotecas...op. cit. 20. p. 46 y nota 31.

${ }^{31}$ Sobre las bibliotecas véase, MILLARES, A. (1993): Introducción a la ...op. cit. 5. p. 233; ALONSO, V. (2003): Las primeras bibliotecas...art. cit. 20. pp. 46-49.

${ }^{32}$ STROCKA, V.M. (1981): Römische Bibliotheken, en Gymnasium, LXXXVIII, p. 315.

${ }^{33}$ CAGNAT, R. (1909) Les bibliothèques municipales dans l'empire romain, en Mèmoires de lìcadèmie des ins. et belles lettres, parte I, pp. 1 y ss.

${ }^{34}$ Véase como ejemplo GIL, L. (1985): Censura en el mundo antiguo. Madrid
} 


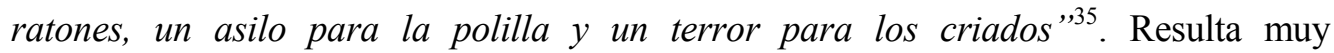
significativo que en el manual de arquitectura de Vitruvio se dedique algunas páginas a cómo deben instalarse estas bibliotecas en las casas. Incluso otros autores imperiales escribieron tratados, hoy perdidos, en los que aconsejaban al lector cómo colocar los libros en sus bibliotecas. De esta forma surgen obras como la de Telefo de Pérgamo Conocer los libros, o la de Erennio Filón Sobre la Elección y adquisición de libros así como El Bibliofilo de Damófilo de Bitinia. ${ }^{36}$

Entre las bibliotecas privadas de época imperial cabe destacar la del poeta Persio, que dejó alrededor de setecientos rollos de libro, así como la del también poeta Silio Itálico, la del satírico Marcial o del escritor Plinio el Joven, donde como en otras casas anónimas podían encontrarse colecciones de interés literario además de colecciones especializadas. ${ }^{37}$

Esta demanda cada vez mayor de literatura por parte de la sociedad dio como resultado la aparición del Codex, una nueva forma de libro que sustituyó al rollo de papiro a lo largo del siglo II d.C., aunque con mayor desarrollo a partir del bajo imperio. El códice es el libro con páginas, mucho más manejable que el papiro, tanto para leer como para situarlo en las bibliotecas (simplemente tumbados en las estanterías) y sobre todo de menor costo ${ }^{38}$. El codex es el medio a través del cual se transformarían las prácticas de lecturas de la Antigüedad a las del Medievo. Así, de caracterizar la lectura el otium romano en jardines y porches así como en plazas y calles, se pasará a los espacios cerrados de las iglesias, de las celdas, de escuelas religiosas y cortes señoriales donde, casi únicamente, se leían las escrituras sagradas y textos de enriquecimiento espiritual a través de los códices. ${ }^{39}$

\section{LA "OSCURA" EDAD MEDIA}

El eclipse del Imperio Romano supuso para los intelectuales de la época una hecatombe de enormes dimensiones. Dichos cambios que se dan a lo largo del siglo V d.C., van a dar al traste con lo que conocemos como cultura clásica -al menos en el lado occidental del Imperio-. Siglos después perdurará la idea en la sociedad europea de dicha pérdida, así como se hará todo lo posible para intentar su vuelta. Pero no nos adelantemos a los acontecimientos. Ante el devastado Imperio, las ciudades habían sido abandonadas de forma paulatina, primero por las elites, más tarde por el resto de la población, que se va instalando en ámbitos más rurales. Así, las ciudades que logran

${ }^{35}$ Cifrado en REYES, A. (1955): Libros y Libreros. México. p. 37.

${ }^{36}$ Cifrados en CAVALLO, G. y CHARTIER, R. (2001): Historia de la lectura ...op. cit.14. p. 16

${ }^{37}$ KLEBERG, T. (1995): Libros y libreros...op. cit. 13. pp. 84-85.

${ }^{38}$ Sobre las características del Codex, véase MILLARES, A. (1993): Introducción a la historia...op. cit.5. pp.30-31.

${ }^{39}$ En la Antigüedad era costumbre leer tumbado en la Kline griega o en el Lectus romano estando directamente relacionada con el Otium. Esta característica se perderá en la edad media, pues las lecturas está asociadas a otros tipos de interés. MANGUEL, A. (2002): Una historia de ...op. cit. 28. pp. 222223. 
sobrevivir al abandono quedan en su mayoría con una gran depresión interna. El cristianismo, religión oficial del Imperio desde Constantino, juega un papel importante en estos primeros siglos, pues debido al caos reinante surgen todo tipo de focos que interpretan de variada forma las Escrituras, lo que desde la jerarquía oficial se intenta erradicar. De esta manera, y por poner un ejemplo, en el 540 San Benito de Nursia da forma a las normas del Monacato, dándole la espalda a otras configuraciones de vida religiosa que habían surgido.

Así la cultura escrita y el saber se tuvieron que refugiar en monasterios, donde los religiosos se ocupaban de su conservación, a la vez que se hacían copias de manuscritos. En efecto, para los siglos IX y X, durante las invasiones vikingas, magiares y musulmanas en algunos puntos del Imperio Carolingio, hizo que se conservaran estos depósitos de saber, así como el aprendizaje del latín. Pero no podemos caer en el fallo de creer que sólo la cultura cristiana preservó documentos, pues por poner un ejemplo, a finales del siglo X Ibn Al-Nadim publicaba su "AlFhrist", donde catalogaba las Letras y las Ciencias, siguiendo los fondos de la biblioteca de Bagdad. Incluso son los árabes los que conforman la posiblemente primera gran biblioteca en la península ibérica. Hablamos del Califato de Córdoba que durante el reinado de Hixam II, entre los siglos X y XI, llegó a concentrar 600.000 volúmenes ${ }^{40}$.

Las bibliotecas durante la primera Edad Media se encontraban casi exclusivamente en los monasterios: Monte Cassino, Fulda, Ripoll, Santa María de la Huerta, etc. En Europa oriental destacaron las importantes bibliotecas de los monasterios bizantinos, especialmente el del monte Athos. Durante todo este tiempo el libro tuvo carácter de cosa o bien sagrado. Ya en esta época aparecen tratados sobre la organización de las bibliotecas, generalmente sistemas para su clasificación o listas de libros. No obstante el acceso era limitado a determinados títulos, lo que impidió la expansión de muchas ideas y frenó la adquisición de conocimientos.

La Universidad era el otro centro de la vida cultural europea, Las escuelas catedralicias se transformaron pronto en las primeras universidades: París, Bolonia, Lovaina, Oxford... aunque en estos momentos no poseían bibliotecas, debido en gran parte al elevado costo de los libros. Aun así en lugares como Chartres, Montpellier, Bolonia, Reins,... se estudiaban las que se consideraban tres ramas superiores del saber: Medicina, Derecho y Teología. Habrá que esperar a los últimos momentos de la Baja Edad Media para que en ciertas ciudades de la península italiana surgiera un nuevo movimiento que abrirá un nuevo horizonte para la Documentación.

Y es así como las bibliotecas universitarias difundieron el libro de forma mucho más eficaz, originaron el abandono de las antiguas bibliotecas monacales -Richard de Bury en el Philobiblion se queja del abandono en que estas se encuentran- ${ }^{41}$. El final de la Edad Media marca la ruptura definitiva con la religión como centro de la cultura humana y el regreso a los clásicos. En esta época se comienzan a formar excelentes bibliotecas privadas y aparece la figura del bibliólogo: merece la pena destacar la figura

\footnotetext{
${ }^{40}$ Op. cit. Pág. 29.

${ }^{41}$ De Bury, Richard. Filobiblión: muy hermoso tratado sobre el amor a los libros. Salamanca: Junta de Castilla y León, 2001. 158 p.
} 
de Petrarca, que no solo formó la biblioteca privada más importante de su época sino que se preocupó por depurar a los clásicos latinos de los errores que a los largo de los años se habían deslizado en la copia de sus libros.

\section{EL RENACIMIENTO Y LA IMPRENTA}

En el corpus de las ciudades podemos ver bien esa evolución que sirve a los historiadores para marcar pautas, épocas o momentos. Hablando más claramente, y permitiéndonos una licencia, somos incapaces de poner un límite exacto entre la Edad Media y la Moderna. Lo que sí está claro es que existió una transformación paulatina de las sociedades europeas, que junto a la aparición o descubrimiento de ciertos hitos históricos, nos permite afirmar que a finales del siglo XV, inicios del XVI, estamos en una nueva etapa en la historia del hombre. Fue hasta el siglo SVI cuando se redescubren las ideas de la cultura clásica, cuando Europa "despierta de su largo sueño".

Como decíamos, las ciudades son fiel reflejo de ello, con el paso de las décadas se habían vuelto más seguras para la población: Inmensas murallas y fortificaciones las rodeaban y protegían. Y es en ellas donde surge una de las principales piezas de la nueva etapa a la que estamos haciendo referencia en este epígrafe: nos referimos a la imprenta $^{42}$. Es en Maguncia donde Johannes Gutenberg comienza realizando pruebas sirviéndose de caracteres metálicos y móviles, apareciendo en un breve periodo de tiempo de competidores. Estamos en 1450 y dicha máquina dará al movimiento Humanista una base, no sólo para reproducir los nuevos estudios y escritos, sino además para recuperar textos clásicos que ahora empiezan a estar al alcance de "casi todos".

Podemos decir que la imprenta nace como evolución natural de la historia, donde se multiplicaron los libros, a la vez que los recursos científicos, lo que hizo que algunos intelectuales de la época les surgiera la necesidad de aglutinar estas ramas del saber. ${ }^{43}$ De esta manera encontramos a Conrad Gesner, quien definió en su "Biblioteca Universalis" un total de 15.000 obras, convirtiéndose en el primer repertorio de carácter general impreso. Johannes Heidenberg Tritheim, es otro de esos nombres del

\footnotetext{
${ }^{42}$ No podemos dejar pasar la oportunidad para cuanto menos dedicar unas breves líneas a la invención de la imprenta. Tenemos que remontarnos al 150 d.C. para datar la creación del papel de celulosa en China por Ts'ai. Tuvieron que pasar hasta seis siglos para que lo descubrieran los árabes, y casi otros tantos en llegar a Europa. Es en 1009, en la península ibérica, dato que no nos debe extrañar teniendo en cuanta que estamos en época andalusí. Respecto a la imprenta en sí, vuelven a ser los japoneses los primeros en apuntarse el tanto allá en 770, seguidos de los chinos en el 868.

${ }^{43}$ El invento de la imprenta se ha comentado siempre como una innovación revolucionaria: revolución en la técnica, revolución en el pensamiento y en las ideas, en los hábitos de lectura, en la multiplicación de los libros, en el número de lectores. El éxito de la imprenta no implicó la destrucción de aquello que se quería superar, al contrario, significó su multiplicación. La imprenta, como antes el alfabeto, participó directamente en el crecimiento cultural de la humanidad, pues los libros impresos fijaron tanto las nuevas invenciones como los descubrimientos científicos. En: Moreiro González, José Antonio. "Introducción bibliográfica y conceptual al estudio evolutivo de la documentación". PPU, Barcelona, 1990.
} 
Renacimiento que brilla con luz propia. El monje benedictino realizó el "Liber descriptoribus ecclesiasticis", que compilaba todas las obras publicadas sobre temas religiosos. Tritheim supo rodearse de estudiosos de la época en su monasterio de Sponheim, y más tarde en Wüszburg, donde ofreció cobijo a personalidades del renacimiento europeo como Celtis, Reuchlin, Agrippa, Gaguin o De Bouelles ${ }^{44}$.

Antes de continuar nuestro periplo, nos detendremos por su cercanía, y por qué no decirlo, por el interés que fluye su personaje para la historia de la documentación, en la persona de Hernando Colón. Hijo del navegante Cristóbal Colón, que no podía negar ser originario de su tiempo. Nace en Córdoba, bien avanzado el Quatrocciento, y se sabe de su pasión por los libros desde temprana edad. Acompañó a su padre en el cuarto y último viaje a las Indias -el cuál le causará gran impresión en su joven personalidad-, y en su precipitada vuelta deja olvidado una serie de arcas que contenían algo más de 238 volúmenes, y que poco después reclamaba. Así, Hernando Colón vive de primera mano variados momentos históricos como la aparición de la imprenta, el descubrimiento de nuevas tierras al otro lado del Océano,...lo que quizás pudiera explicar su dedicación, afición e incluso obsesión por los libros. Hay un dato más que lo convierte en un renacentista puro: su gusto por la cosmografía. Pero nos centraremos en su papel como bibliólogo, donde por cierto hay que decir que fue un adelantado de su tiempo. En vida logró reunir con casi toda certeza algo más de 15.000 volúmenes que fue recopilando a través de compras, donaciones o regalos. Así se conformó la conocida "Biblioteca Colombina", que se aposentó hasta cinco años después de su muerte en su Palacio de Puerta de Goles en Sevilla. Pero lo más llamativo sin duda, y lo que le hace merecedor de tanto interés era su forma de catalogación. Según nos cuenta su biógrafo Juan Guillén:

"construía un verdadero registro de obras con la ficha bibliográfica de cada una de ellas: anotaba el nombre del autor y el título de la obra, si era impresa o manuscrita, lugar de impresión e incluso a veces, el impresor [...] lugar y fecha de la compra, el precio en la moneda nacional y su equivalencia en ducados... ${ }^{45}$.

Cabe destacar que Colón en 1513, ya tenía proyectada su biblioteca, y en 1522 formó al equipo que trabajaría en ella.

Por último, López Yepes nos señala que en esta época los cambios que se originaron a lo largo de los siglos XVI y XVII y que dieron lugar a lo que se ha llamado revolución científica o explosión de la ciencia moderna, constituyeron la base para el

\footnotetext{
${ }^{44}$ Nos gustaría hacer hincapié llegado este momento, en la idea en la que Peter Burke critica la forma que hasta no hace mucho tiempo se ha venido realizando las investigaciones sobre el Renacimiento. Según él se le ha dado demasiada importancia a los estudiosos en particular, olvidando quizás los grupos que conformaban los mismos, así como las redes sociales establecidas entre ellos. El caso de las abadías regentadas por Thirtheim son un buen ejemplo. En Burke, Peter "El Renacimiento Europeo". Crítica, Barcelona, 2000. Pág. 19.

${ }^{45}$ En Guillén, Juan "Hernando Colón. Humanismo y bibliofilia". Fundación José Manuel Lara, Sevilla, 2004. Pág. 83.
} 
conocimiento de los orígenes de las revistas científicas o especializadas. ${ }^{46}$ Sin duda, un dato importante para el campo de la Documentación.

\section{EL BARROCO Y LA CIENCIA}

Todo llega a su fin, y no fue distinto con el Renacimiento y todo lo que esto suponía. A inicios del siglo XVII hay autores como Quevedo, D'Aubigué o Donne que expresaban su sensación de inestabilidad y cambio. Como buenos hijos de su tiempo, no estaban equivocados, pues desde hacía algunos lustros se estaba dando lo que se ha conocido como desmitificación de los Antiguos. Y es que el propio Renacimiento había producido una serie de intelectuales que superarían el ámbito cultural en el que fueron engendrados. Hablamos entre otros de Galileo, Da Vinci, Descartes o Copérnico. El XVII será el siglo de las revoluciones científicas.

Pero antes de continuar, nos gustaría exponer que nos encontramos en años donde se consolidaron los grandes Imperios europeos; aunque algunas monarquías como la española contenían una profunda depresión. Los reyes se contemplan como los elegidos por la mano Divina, muchos hacían dejación de deberes en Ministros o Validos, la represión contra minorías y vencidos era la mayor en siglos de Historia, así ejercían su poder en el más puro Absolutismo. Incluso, las Asambleas representativas heredadas de la Edad Media fueron perdiendo poder en toda Europa ${ }^{47}$. En el campo del Arte, aunque sigue el gusto por los elementos clásicos bien definidos, se empezó a jugar con la luz complacen las gradaciones nocturnas o atmosféricas-, agrada el retrato y el paisaje, y aparecen maestros en la materia como Rubens, Rembrant, Caravaggio o Velázquez. Éstos servirán en muchos casos de narradores de la crisis social y moral, pero también de los avances de la ciencia. Así y como decíamos, los avances en la sabiduría se desarrollan en distintos campos, desde la filosofía, hasta la física, pasando por la astronomía.

Esto haría que se escribiesen "relaciones descriptivas de la literatura de los temas que trataban"48. De esta manera en 1620 se publicó el primer catalogo bibliotecario general que servía como lista de búsqueda, llamado "Bodlein Catalogue" de Thomas James y Thomas Bradley. Pero no fue el único, poco después en 1629, León Pinelo escribe "Epítome de la biblioteca oriental y occidental, náutica y geográfica"; en 1672 se publica en Roma la "Bibliotheca Hispana" de Nicolás Antonio; y a continuación "Bibliographia jurídica et política", en 1680 por Corneille de Beugheum.

Y posteriormente el siglo de las luces, el XVIII, periodo donde se quiso renovar el ambiente cultural desde las clases dirigentes: nos referimos al Despotismo Ilustrado.

\footnotetext{
${ }^{46}$ López Yepes, José. La documentación como disciplina: teoría e historia. Pamplona: EUNSA, 1995. p. 42.

47 "El Zemski Sobor ruso se reunió por última vez en 1653, las Cortes castellanas en 1665, la Dieta de Brandeburgo perdió su poder efectivo a partir de 1653, y el Parlamento de París buena parte de su autoridad en 1670.", en Tenenti, Alberto "La formación del mundo moderno", Crítica, Barcelona, 1985. Pág. 363.

${ }^{48}$ En Arnau Rived, Pilar. Op. cit. Pág. 56.
} 
Por este motivo las ciencias continúan su avance imparable y se apuesta por su divulgación; que mejor ejemplo de lo que exponemos que el trabajo de Diderot y D'Alambert con la "Encyclopédie". ${ }^{49}$

En España la Ilustración está muy relacionada con la llegada de la nueva dinastía de los Borbones tras la larga guerra de Sucesión (1700-1714), que enfrentó a Francia y parte de la península, que apoyaban a Felipe de Borbón; contra Inglaterra, Holanda, Austria y posteriormente Portugal, que defendían los derechos sucesorios del Archiduque Carlos. El triunfo del primero y su nombramiento como rey, tras la Paz de Utrecht, hizo que una nueva dinastía entrara en el viejo Imperio, así como trajera nuevas ideas. Intelectuales como Feijoo apoyaron abiertamente a los nuevos monarcas ilustrados. Para realizar una mejora del reinado en todos sus aspectos se fundan a lo largo de toda la centuria Reales Academias y Sociedades de Amigos del País, así y sobre todo a partir de la segunda mitad de siglo se interviene directamente desde el gobierno, como por ejemplo secularizando las bibliotecas. Es durante el reinado de Carlos III, rey ilustrado por excelencia en España, cuando la Biblioteca Real inicia la publicación de repertorios y catálogos.

Sin embargo la mala situación económica que se llevaba arrastrando desde hacía varios lustros en el reino francés, así como la inoperancia para gobernar de su monarca Luis XVI, más las ideas provenientes de la Ilustración de autores como Voltaire, Rousseau o Montesquieu, promovieron en 1789 la Revolución francesa, con la cuál se daba fin en dicho país al Antiguo Régimen, abriéndose las puertas a lo que conocemos como una nueva era histórica.

\section{EL SIGLO DE LAS LUCES}

Unos años antes ya se estaban sentando las bases en Inglaterra de lo que conocemos como la Revolución Industrial. Se comienza a dar en circuitos urbanos, los cuales basaban su riqueza en la existencia de unas prósperas clases medias y en el comercio que se producía. Es en el país anglosajón dicho hito por las características que este

\footnotetext{
${ }^{49}$ La Enciclopedia francesa del s. XVIII surge casi de forma anecdótica al aceptar Diderot la traducción del diccionario de Chambers, Cyclopaedia o Universal Dictionary of Art and Sciences (1728), inicialmente confiada a otros, que Diderot comenzó más bien a transformar y reconstruir que simplemente a traducir. Los editores aceptaron la sugerencia de publicar una obra original y así nació el proyecto o Prospecto de la Enciclopedia en 1750. Diderot pidió la colaboración de d'Alembert, quien se encargó de redactar el Discurso preliminar. En él d'Alembert presenta la Enciclopedia como un sistema de todos los conocimientos humanos; al ser éstos inabarcables, busca una manera de representarlos en síntesis y, para ello, sigue la clasificación del «árbol del canciller Bacon», que divide la actuación de las facultades intelectuales y fabriles del hombre en facultades de memoria, razón e imaginación. La memoria es la sede de la experiencia o del conocimiento directo (historia); la razón, de la reflexión hecha con el razonamiento (filosofía); la imaginación, de la imitación reflexiva (bellas artes o poesía). Cada uno de estos grandes grupos de ciencias y actividades humanas se subdivide en muchos otros apartados que configuran, en definitiva, el árbol «de las ciencias, de las artes y de los oficios». "La Ilustración". En: Sociedad Andaluza de Educación Matemática "Thales". Disponible en: http://thales.cica.es/rd/Recursos/rd99/ed99-025701/enciclo.html.
} 
había logrado reunir durante su etapa en la Edad Moderna: el sistema de distribución de la tierra, las innovaciones técnicas que se dan en su territorio, así como la existencia de un mercado que diera salida a los productos creados, son buena parte de ellas. Surgen nuevos términos, nuevas condiciones en la vida cotidiana de la población. Así, para producir energía, se comienza a usar el carbón mineral, y aparecen innovaciones técnicas como la máquina de vapor o la calefacción. Pero no sólo se producirán cambios importantes en el campo de la ciencia: en el mundo de la política y la sociedad empiezan a fraguarse modificaciones que junto a las anteriores, expondrán los cimientos de nuestra sociedad actual. De esta forma, tras siglos de superioridad aristocrática, los movimientos sociales buscan la igualdad, dándose a través de toda esta centuria distintos tipos de avances. Aparecen en escena las ideologías, siendo de las más representativas el liberalismo, el socialismo y el nacionalismo. Mucho antes, como comentábamos al final del epígrafe anterior, desaparecía el Antiguo Régimen, dando paso a sistemas Constitucionales, aunque la mayoría conservarían la Monarquía como figura institucional de primer orden. A las revoluciones americana y francesa habría que sumar la de los años 1830 o 1848, siendo nuevamente Francia el foco inicial de las mismas, aunque seguidamente se extendían por otras ciudades europeas. En la última a la que hacemos referencia se aprueba el sufragio universal, la jornada laboral de 10 horas o el derecho a la huelga, lo cual sembrará un precedente en la historia europea. Aun así en 1851 los avances sociales conseguidos desaparecen con el golpe de estado de Luis Napoleón.

$\mathrm{Al}$ otro lado del Atlántico en estos años nacía Mevil Dewey, más concretamente en una localidad del norte del estado de New York. Realmente faltaba poco para que comenzara la guerra de Secesión entre los estados del norte y el sur, que finalizará en 1865 con la derrota de los segundos y la implantación de uno de los primeros sistemas democráticos. Este hecho pudo realizarse por las propias características de los estados norteamericanos: por un lado predominaba el ideal liberal heredado de su antigua metrópoli anglosajona y por otro, no había existido con anterioridad una sociedad del Antiguo Régimen, a la cual destruir, tal como sí había -y estaba pasando-, en Europa. Un último aspecto que nos gustaría destacar es la desaparición conforme avanzaba el siglo XIX de la mayoría de los grandes imperios europeos, sobreviviendo sólo el ruso, el austrohúngaro y el turco. Así aparece el término "estado-nación", creándose en la década de los años 60 países como Italia o Alemania.

Antes citábamos puntualmente el nacimiento de una de las figuras por excelencia de la historia reciente de la documentación. Como podemos ver ésta fue la situación de cambio rápido y sucinto de la sociedad en la que le tocó nacer. Pero es obligatorio mencionar también que en este tiempo aparecieron en escena otros personajes, que al más puro estilo de este momento histórico, revolucionaron la Documentación: Paul Otlet y Henri La Fontaine. El primero nace en Bruselas en 1868, viajando en plena juventud a París donde estudia Sociología, Derecho, Economía e Historia, doctorándose poco después. En esta época muchas de sus inquietudes se realizan en la Sociedad de Estudios Sociales y Políticos, donde conoce a La Fontaine. Éste por su parte, había nacido en la misma ciudad 12 años antes, y trabajaba de encargado de la Sección Bibliográfica de dicha institución. 
Nos encontramos ahora en lo que se ha llamado Segunda Revolución Industrial, dándose importantísimos avances en las ciencias, sustituyéndose el hierro por el acero, así como incuestionables avances en la química con nombres como Liebig, Solyear o Nobel. Todo esto que venimos relatando, más las novedades producidas en esta segunda etapa proindustrial, creemos tienen una total relevancia dentro de la historia de la documentación. Las revoluciones se venían dando en ámbitos como el social, económico y cultural, así no debe extrañar que sea ahora cuando se dan grandes avances en este campo. Muchos han llamado a este momento de la historia la Belle Epoqué, la sociedad próspera de finales del siglo XIX que sirvió de caldo de cultivo para que se dieran estos hechos. Así pues en estos años Otlet y La Fontaine crean el Instituto Internacional de Bibliografía Sociológica, donde realizan un catálogo con resúmenes de los contenidos de las publicaciones. Además fueron más allá, idearon un sistema de fichas, las cuales con el paso del tiempo se irían renovando. Un año después de la creación de la entidad coinciden con el norteamericano Dewey, el cual unos lustros antes, con tan sólo 17 años trabaja de profesor rural en su estado natal, y en 1876 edita el "Decimal Classification System"; una década después organizaba cursos pioneros en el campo de la biblioteconomía en el Columbia College. Y así y volviendo al encuentro de 1894, es cuando crean la CDU, a la vez que elaboran un Repertorio Bibliográfico Universal. Esto es llevado a la Conferencia Internacional de Bruselas, lo que permite crear el Instituto Internacional de Bibliografía (IIB).

El siglo XX seguirá la evolución de su antecesor con innovaciones técnicas, por lo que, por ejemplo, se empezará a usar la electricidad y el petróleo como creadores de energía. De esta manera estamos de nuevo en una época próspera, donde el pacifismo invadió las capas de la sociedad, sin ir más lejos del tema que nos compite, creemos muy significativo el dato que dice que Henri La Fontaine gana el Premio Nobel de la Paz en 1913. Incluso unos años antes existía propaganda antimilitarista en los medios revolucionarios europeos. En Ámsterdam llegó a celebrarse un congreso internacional sobre dicho tema, donde se acordó la fundación de una Internacional Antimilitarista ${ }^{50}$. Sin embargo, tan sólo meses después, y más concretamente a raíz del atentado que sufrió el heredero al trono austriaco el 28 de junio de 1928 en Serbia, comienza la Gran Guerra, la cual finaliza con el Tratado de Versalles, sufriendo el IIB los típicos envites de un conflicto bélico de estas dimensiones. Una vez firmada la paz no fue definitiva ni mucho menos, pues por ejemplo Francia jugó un papel humillador hacia la derrotada Alemania, que en cierto modo provocó que los nacionalismos se realzaran. Mientras, EE.UU. se enriquecía vendiendo sus productos a los países desolados por la confrontación, actitudes éstas, que a la larga darán unos resultados muy negativos como más tarde veremos. En 1925 se realizó la Conferencia de Locarno, la cual sirvió para ratificar lo firmado seis años antes, a la vez que se conforma la Sociedad de Naciones con un papel arbitral. De esta manera estamos de nuevo en una época de prosperidad

\footnotetext{
${ }^{50}$ Para saber más datos sobre dicha cuestión remitirse a Vallina, Pedro "Mis memorias". Libre Pensamiento, Madrid, 2000. Pág. 124. Éste afirma que en los medios obreros se estaba muy convencidos del triunfo de la paz, a pesar de las voces de alarma que respecto al tema bélico estaban surgiendo desde hacía tiempo.
} 
económica. En estos años Otlet y La Fontaine continuaron sus trabajos en el IIB, los cuales fueron elevados hasta la denostada Sociedad de Naciones. A la vez de instituciones como la que citamos, de corte internacional, empezaron a crearse otras a nivel nacional. Por ejemplo en 1921 el Nederlands Instituu voor Documentatie, con Donker Duyvis al frente. Más curioso es el caso norteamericano, donde en plena resaca de la crisis económica, en 1930, surge el American Documentation Institute ${ }^{51}$ (ADI), ¿se apostaría por el mismo para buscar mejoras y avances tras el crack del 29?. Siguiendo esta idea hay que exponer que la propia institución de corte internacional seguirá dando grandes pasos en esta década. Y es que en 1931 pasa a llamarse Instituto Internacional de Documentación (IID), para en 1938 tomar el nombre de Federación Internacional de Documentación (FID) ahora bajo la batuta de Duyvis, quien tomaba el relevo de unos ya venerables Otlet y La Fontaine.

Mientras tanto y de manera casi vertiginosa y con el trasfondo de la guerra civil española, los hechos prebélicos se suceden rápidamente. Los fascismos estaban instalados desde hace algunos años en el poder de países como Alemania, Italia y más recientemente, España. El 1 de septiembre de 1939 Alemania invade Polonia, creándose como reacción dos bloques que se enfrentarán en la conocida como II Guerra Mundial. Por un lado, el Aliado, conformado por Francia y Reino Unido, sumándoseles en 1941 la Unión Soviética y EE.UU. Por otro Alemania, a la que se le uniría en 1940 Italia, y en 1941 Japón. Tras los primeros años de horrenda guerra y hegemonía Nazi, en 1943 empiezan a girarse las tornas. Mussolini se rinde en Italia, los aliados invaden Sicilia, sin embargo los nazis retomaron el norte de Italia, quedándose el choque estancado. A partir de 1944 la guerra se sucede de forma rápida. El 6 de junio se toma Normandía y el 25 de agosto París. De Enero a Mayo de 1945 se da la ofensiva soviética sobre la Alemania oriental, así como la anglo-norteamericana al otro lado del Rhin. Así las consecuencias de la misma son altamente conocidas: países completamente destrozados, 55 millones de personas muertas,...Poco después de la finalización de la contienda surge el término "Guerra Fría", que si bien no fue creado por el periodista Walter Lippmann, unas de sus obras, curiosamente así titulada en 1947, bien ayudó a difundirlo. Esta situación surge con la división del bloque vencedor, encabezados cada uno por EE.UU. y Rusia. De esta manera asistiremos desde este momento, y hasta los años 90, a una profunda división de la civilización, pues ambos bloques representaban de manera totalmente antagónica la configuración de sus respectivos sistemas político, económico y social. Esta diferencia llevó a los dos países a una carrera que podemos afirmar, copó todas las estructuras de un estado, por lo que no iba a ser menos la documentación. La influencia en ésta última, de este nuevo status quo mundial lo vemos presente por ejemplo en el problema que se planteó para cubrir con resúmenes analíticos toda la información internacional de los ámbitos científicos, como bien nos dice Moreiro González, “...se volvió más preocupante en la década de los $50^{\text {”,52. }}$.

\footnotetext{
${ }^{51}$ Nos dice J. H. Shera: "concebido en un principio como una organización de representantes de las diversas sociedades eruditas del país que buscaban nuevos medios auxiliares y cientificos...". En Moreiro González, J. A. Op cit. pág. 95.

${ }^{52}$ Op cit. pág. 96.
} 
Siguiendo las indicaciones del profesor "la creación de trabajos es tan extensa que el Chemical Abstract de 1952 tenía mayor volumen de datos que los referidos a la década de 1907-1916". Otro dato indicativo de la nueva situación mundial y su influencia en el mundo de la documentación es el interés levantado en muchos gobiernos en crear instituciones nacionales de información científica, frente al monopolio cada vez más imperante de los EE.UU. Por ejemplo Francia o Rusia. Respecto al segundo, creó siguiendo la estela de Otlet el VINITI, cuyo centro estaba en Moscú y que en 1953 publica su primer repertorio bibliográfico.

\section{BIBLIOGRAFÍA}

ALONSO, V. (2003): Las primeras bibliotecas en Roma (romoteca), en Revista General de Información y Documentación, 13, n 1. pp. 37-49.

ARNAU Rived, Pilar. "Documentación. Hitos históricos". Madrid, Mundarnau, 1999.

BAHAMONDE, Angel y Villares, Ramon. "El mundo contemporáneo. Siglos XIX y XX". Taurus, Madrid, 2001.

BLANCK, H. (1992): Das Buch der Antike. Munich.

BURKE, Peter. "El Renacimiento Europeo". Crítica, Barcelona, 2000.

CAGNAT, R. (1909): Les bibliothèques municipales dans l'empire romain, eb Memoires de l'Ácademie des ins et belles lettres. Part I.

CALLMER, C. (1944): Die Antiken bibliotheken. Leizpig.

CAVALLO, G. (2001): Entre el volumen y el codex. La lectura en el mundo romano, en Cavallo G, y Chartier, R. (dir), Historia de la lectura en el mundo occidental. pp. 109-142.

CAVAllO, G. y CHARTIER, R.(2001): Historia de la lectura en el mundo occidental. Madrid.

CASSON, L. (2001) : Libraries in the Ancient world. New Heaven y Londres.

DAIN, A. (1949): Les manuscrits. París.

DE BURY, Richard. Filobiblión: muy hermoso tratado sobre el amor a los libros. Salamanca: Junta de Castilla y León, 2001. 158 p.

ESCOLAR Sobrino, Hipólito. Historia de las bibliotecas. $3^{\text {a }}$. Ed. Salamanca. Madrid: Fundación Germán Sánchez Ruipérez: Pirámide, 1990. Pág. 16.

FERNÁNDEZ Álvarez, Manuel. "España y los españoles en los tiempos modernos". Universidad de Salamanca, Salamanca, 1979.

GIL, L. (1985): Censura en el mundo antiguo. Madrid.

GÓMEZ Espelosín, Francisco Javier. "Historia de Grecia Antigua", Akal, Madrid, 2001.

GUILLÉN, Juan. "Hernando Colón. Humanismo y bibliofilia”. Fundación José Manuel Lara, Sevilla, 2004.

HAESLST, J. V. (1989): Les origines du codex, en Blanchard (ed.), Les débuts du codex, Brepols-Turhout.

KLEBERG, T.(1995): Libros, editores y público en el mundo antiguo. Madrid.

KOENISGSBERGER, H. G. "La Edad Media 400-1500”, Crítica, Barcelona, 1991. 
LÓPEZ Yepes, José. La documentación como disciplina: teoría e historia. Pamplona: EUNSA, 1995.337 p.

POSNER, E. (1972): Archives in the Ancient World. Cambridge.

MANGUEL, A. (2002): Una historia de la lectura. Madrid.

MILLARES, A. (1993): Introducción a la historia del Libro y de las Bibliotecas. Madrid. 5 ed.

MOREIRO González, José Antonio. "Introducción bibliográfica y conceptual al estudio evolutivo de la documentación". PPU, Barcelona, 1990.

NIEDDU, G. F. (1984): Testo, scrittura, libro nella Grecia arcaica e classica: note e osservazioni sulla prosa scientifico- filosofica, en Scrittura e Civilità, VII, pp. 213-61.

ONG, W.J. (1982):Orality and Literacy. The technologizing of the world. LondresNueva York.

PAREDES, Javier (coord.). "Historia Contemporánea de España (siglo XX)", Ariel, Barcelona, 1991.

REYES, A. (1955): Libros y Libreros. México.

RUMEU DE ARMAS, Antonio. "Hernando Colón y su época". Real Academia Sevillana de Buenas Letras, Sevilla, 1991.

SKEAT, T. C. (1983): The birth of teh codex. Oxford.

SAGAN, Carl. "En la orilla del océano cósmico" [Vídeo]. Barcelona: Midas Home Vídeo, 1990. Serie Cosmos.

STROCKA, V. M. (1981): Römische Bibliotheken, en Gymnasium.

SVENBRO, J. (1988): Phrasikelia. Anthopologie de la lecture en Grèece ancienne. París.

TENENTI, Alberto "La formación del mundo moderno", Crítica, Barcelona, 1985.

ZANKER, P. (1992): Augusto y el poder de las imágenes. Madrid. 